\title{
Rice Supply Patterns in Kalimantan Selatan: Part of solution for regional food security
}

\author{
Arief RM Akbar ${ }^{1}$, Alan Dwi Wibowo ${ }^{2}$, Alia Rahmi ${ }^{3}$ and Sigit Prabawa ${ }^{4}$
}

\begin{abstract}
South Kalimantan is a largest rice producer in Kalimantan island. More than five years its rice met by their own production, moreover it has supplied to other area such as Kalimantan Tengah, Kalimantan Timur and Kalimantan Utara. In many studies, rice stocks play a critical role in determining the regional's food security. In recent issues, rice stocks has a wide impact on an array of economic, political, societal stabilities. Unfortunately, most of the land in Kalimantan Selatan is classified as wetlands, where the land productivity is low. Therefore, this study analyzes rice supply patterns in Kalimantan Selatan in order to provide policies development toward rice self-sufficiency. This research is using system dynamics approach to explore the system which then develop any alternatives of rice policies. Eventually, this study provides evidences for the need to consider rice supply system in the regional's food security policies.
\end{abstract}

Keywords-policy, rice, simulation, supply pattern, system dynamics

\section{INTRODUCTION}

$\mathbf{T}$ HE one of the responsibility's government is to manage staple food availability, against avoid an array of economic, societal and political instability. Therefore, rice as a staple food in Kalimantan Selatan has to be managed as a strategic commodities [1]. On the other hand, population is become an important thing which has to be considered in provide rice policies. The increasing of population will lead rice demand uncontrollable.

Food availability not only focus on quantity but also quality, integrity, safety and health [2], the continuity of product, products diversification, price affordability [3] and related information services [4]. In fact, the government is only focus on the quantity. The override other focus lead any protest from the people and may lead a chaos.

As a unique findings, Kalimantan Selatan is listed as top ten rice producer in Indonesia which has a wetlands as a majority lands. Kalimantan Selatan achieve surplus in rice production in the last five years. This lands can only be planted with rice once a year unlike in Java that can be planted as much as 2 to 3 times a year. Kalimantan Selatan has a land structure less suitable for rice [5].

Manuscript received June 30, 2018. This work was supported in part by the National Strategic Grant from Ministry of Research, Technology and Higher Education of Republic of Indonesia.

${ }^{1}$ Agroindustrial Technology Department, Lambung Mangkurat University, Banjarbaru 70714 Indonesia (e-mail: ariefrma@ yahoo.com).

${ }^{2}$ Agroindustrial Technology Department, Lambung Mangkurat University, Banjarbaru 70714 Indonesia, (corresponding author: +62 5114772254 / +62 81150 19 50; fax: +62 511 4772254; e-mail: alan.dwi@unlam.ac.id).

${ }^{3}$ Agroindustrial Technology Department, Lambung Mangkurat University, Banjarbaru 70714 Indonesia (e-mail: alia.rahmi@unlam.ac.id).

${ }^{4}$ Food Science and Technology Department, Universitas Sebelas Maret, Surakarta, 57126, Indonesia (e-mail: sigit_prabowotp@yahoo.co.id).
Rice in Kalimantan Selatan play critical role, foremost in inflation rate. According to the Bank Indonesia Annual Report that rice is one of the commodity that listed on 20 commodities contributor to inflation in Indonesia especially in Kalimantan Selatan. In Kalimantan Selatan, rice has the most influence on the inflation rate. Bank Indonesia also stated that supply and demand of rice in controlling the inflation rate needs to be studied further. In other hands, the Gross Domestic Product number field and horticultural crops occupy the top two positions under the mining and quarrying as a contributor to the economic value [3]. The good managing on rice will lead better economic performance of Kalimantan Selatan indirectly [5].

This study aimed to analyzes rice supply patterns in Kalimantan Selatan in order to provide policies alternatives toward rice self-sufficiency in Kalimantan regional. The outcomes of this study is provide an rice supply model in Kalimantan Selatan. This model will help the government to control regional stability through generate the policies in rice management.

\section{Methodology}

System dynamics (SD) approach was used in this study. It is widely used in study of exploratory modeling. It also has been discussed as an important methodology by sundry researchers [6], on the other hands, [7] said that system dynamic approach focuses on the pattern and behavior of systems composed of feedback loops interactions. Causal loops diagram is a powerful tool to skecth the causal realtionship and help to describe the complex system to simple conceptual system. The art of system dynamics modeling lies in discovering and exploring also capturing the behavior of system into the feedback loops interactions.

Procedural steps in SD modelling is described as follows [8]:

a. Define the main problems to be solved and goals to be achieved

b. Develop a causal loop diagrams

c. Formulate the structure of model (stock and flow diagram, i.e. translating from interaction to mathematical model)

d. Collect the data needed for operation of the model either from historical data and/or from disscusion with the expert.

e. Validate the model

f. Use the model to test the various actions to find the best alternative(s) in order to achieve the goals. 


\section{RESUlT \& DISCUSSION}

The main problem in this study is how the rice supply system can provide rice in self-sufficient in the last five years, meantime the nature of Kalimantan Selatan hardly support in paddy plantation. Based on the main problem, this study should be able to determine the leverage point in the rice system to maintain the supply pattern of rice in Kalimantan Selatan.

Causal loop diagram was developed. It shows causality impact in the system. The causal loop diagram is constructed by mental data processing. The diagram shows variables which has impact to the system and shows structures of the system. Causality diagram of this research is presented in Figure 1.

Furthermore, stock and flow diagram (SFD) is constructued by numerical data processing. Narrowly, the construction of SFD is using data from the previous studies. The primary data is using to verify the connections among teh variable. Expert justification is a powerful in SFD construction. SFD is defining relationship among the variable in form mathematical languange. Four modul is developed in this study which are production, population, consumption, and land. Stock and flows diagram is show in Figure 2 as follows.

Model evaluation is using verification and validation approach. Verification of the model performed by the consistency of each equation and parameters. While, validation is conducted with four types of tests on the system which are comparison of the behavior of the model, extreme conditions test, historical fit and sensitivity analysis.

Historical fit tests is performed on three important variables which are paddy dried grain production variable, population variable, rice stock. The deviation as a result of the test is show $2.3 \%, 0.57 \%$, and $3.13 \%$ respectively. The finding is all highlighted variables less than $10 \%$ deviation, therefore it could be declared that the model is valid. The extreme conditions test was performed on the variable of production variable and new paddy area. There were not show illogical patterns, therefore it could be declared that the model is valid. Sensitivity analysis test shows the variable of rate of rice consumption per capita has good indication. By the changing $10 \%$ gives a deviation of $21 \%$, while the reduction in rate of rice consumption per capita $10 \%$ gives a deviation of $31.40 \%$. It means small changes could give impact on the system significantly. All of the tests show that the model which was developed was valid. The result of model validation is show in Figure 3 as follows.

There are many variable has been found in the model. However, only several variables have a significant impact which called as leverage points. First variable is paddy productivity. All of the policies which will be developed is must be consider to this variable. The rice supply of Kalimantan highly impact by paddy productivity. Paddy productivity is also influenced by many variable such as pest control, seed quality, farmers productivity and nature factors. In order to provide sufficient in rice the governement should focus on productivity.

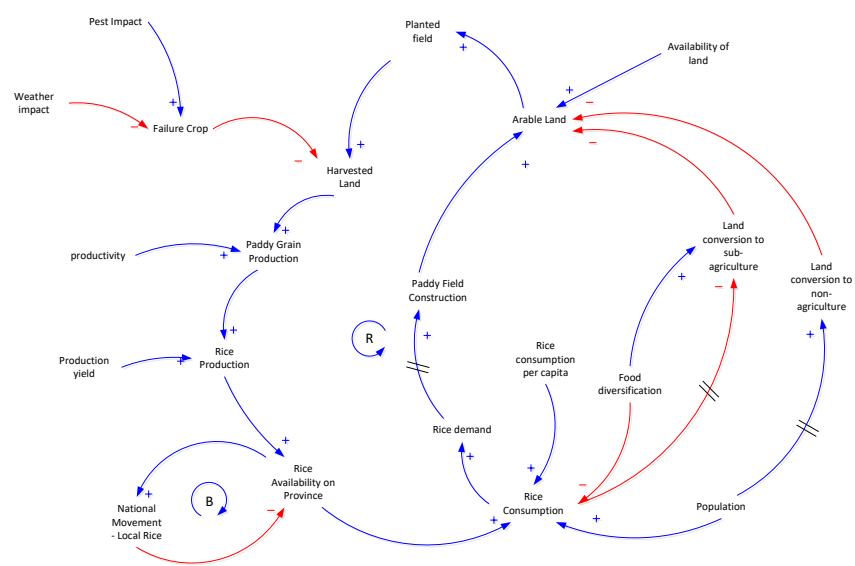

Fig. 1. Causal Loop Diagram

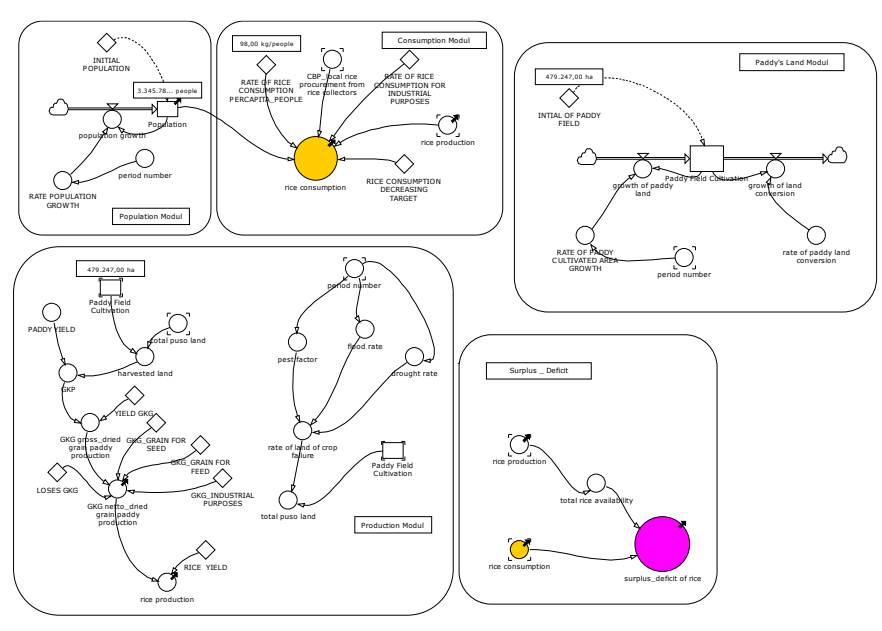

Fig. 2. Stock and flow diagram

The next leverage point is cultivated area. Land conversion is become popular issue today. In Kalimantan Selatan many conversion from paddy land to other purposes such as housing, mining and industry. On the other hands, project of new paddy land development does not show encouraging growth. Potential land is limited, therefore the government should be considered this variable in order to maintain the supply of rice in Kalimantan Selatan. Population is one of the variable which also need to be considered by the governement. In figure 3.a show that population is growing every year. Population will affect rice consumption directly, therefore government need to explore critical factor which affect the growth of population in advanced, then try to control it also provide alternative solution through food diversifications strategy.

Prediction of production of rice in Kalimantan Selatan has been simulated between year 2007 - 2027 (see Figure 4). The result of simulation show Kalimantan Selatan still able to meet the need of rice for Kalimantan Selatan itself and also as supplier for satelite area such as Kalimantan Tengah, half of Kalimantan Timur and Kalimantan Utara. Nevertheless, the government should focus on maintain and control the productivity, paddy land, and population growth. 


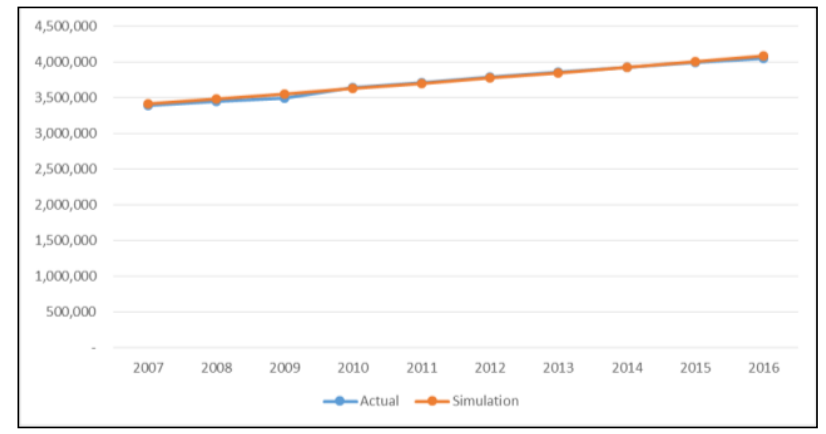

(a) Population of Kalimantan Selatan

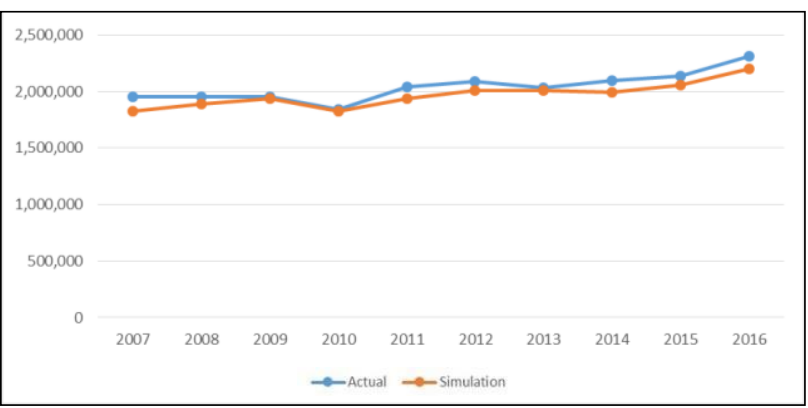

(b) Rice production of Kalimantan Selatan

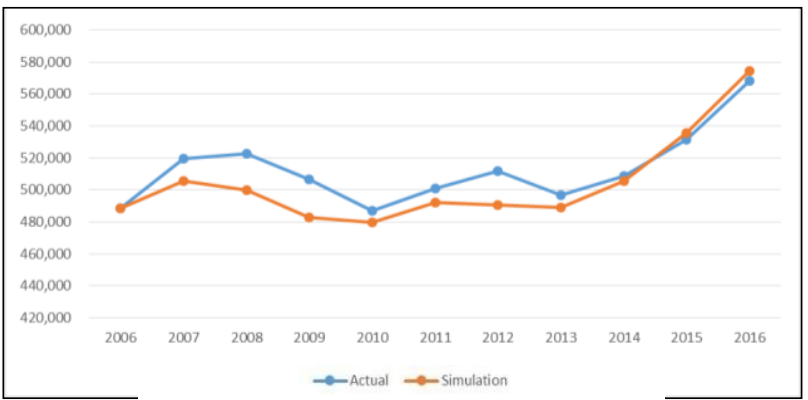

(c) Cultivated area (paddy) of Kalimantan Selatan

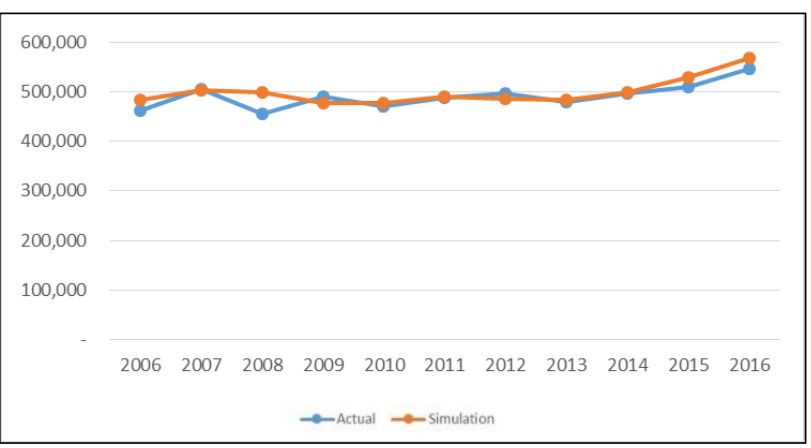

(d) Harvested area of Kalimantan Selatan

Fig. 3. Model Validation

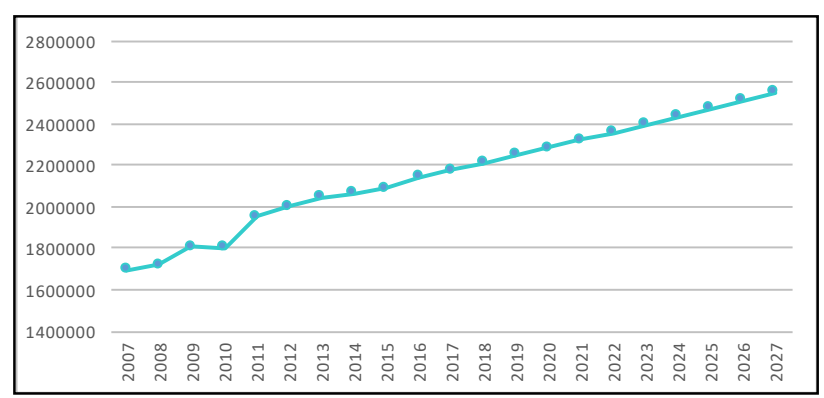

Fig. 4. Production of Rice Simulation in Kalimantan Selatan
Local rice is preferred by people in Kalimantan Selatan, therefore local rice production must be maintained at a certain level that can meet local demand. As for the achievement of rice surplus, several locations support to produce superior rice that has greater productivity, which can be planted twice a year. Apparently this consumption factor is influenced by demography and culture. This superior rice is consumed more by local transmigrants and sent out of Kalimantan Selatan, such as Kalimantan Tengah and Kalimantan Timur. For this reason, the pattern becomes important to be studied further to design a rice supply policy in South Kalimantan. The government also needs to define in more detail the land layout. Land conversion must be controlled so that production numbers can be maintained. Creating rice fields can continue to be pursued but requires great effort. So that the intensification approach becomes important such as the use of good seeds, a mechanization approach, and improving the trade system of rice farming.

\section{CONCLUSION}

Kalimantan Selatan is and will be a rice supplier for many years to come. Several leverage point in rice supply pattern in Kalimantan Selatan should be the main topic in order to development of policies by the government such as productivity in rice production, limited paddy land, and population growth. In different point of view, Kalimantan Selatan will be able to become a regional rice barn principally for Kalimantan and the middle part of Indonesia.

\section{REFERENCES}

[1] Irawan, "National Rice Availability Analysis: A Simulation Study of Systems Dynamics Approach". In Multifunction Agriculture Proceeding. Indonesia, 2005.

[2] Hu, J., Zhang, X., Moga, L M., and Neculita, M., "Modeling and Implementation of the Vagetable Supply Chain Traceability System", Food Control Vol 30, pp. 341-353, 2013.

[3] Wibowo, A D., Surjandari, I., Moeis, A O., "Rice Availability Policy for Industrial Region: Study in Kalimantan Selatan", in Proceeding of The 3rd Asia future Conference Environment \& Coexistance, Kitakyushu, Japan, September 29 - October 2, 2016.

[4] Vorst, J. G. A. J., Tromp, S. O., and Zee, D. J., "Simulation Modelling for Supply Chain Redesign; Integrated Decision making on Product Quality, Sustainability, and Logistics". International Journal of Production Research 47 (23), pp. 6611-6631, 2009.

[5] Kirnadi, A. J. dan Firahmi, N., "Produksi dan Kebutuhan Konsumsi Beras di Kalimantan Selatan (Rice Production and Consumption in Kalimantan Selatan)", Al'Ulum Vol 44 No.2. pp. 1-8, 2010.

[6] Arbnor and Bjerke, Methodology for Creating Business Knowledge, Sage Publication, 1997.

[7] Dinesh Sharma, B.S. Sahay, Amit Sachan, (2004) "Modelling distributor performance index using system dynamics approach", Asia Pacific Journal of Marketing and Logistics, Vol. 16 Issue: 3, pp.37-67, 2004.

[8] Roberts, E.B., Managerial Applications of System Dynamics, MIT Press, Cambridge, MA, 1978. 